\title{
Differential Proteome Analysis of Extracellular Vesicles from Breast Cancer Cell Lines by Chaperone Affinity Enrichment
}

\author{
Steven G. Griffiths ${ }^{1}$, Michelle T. Cormier ${ }^{2,+}$, Aled Clayton ${ }^{3}$ (1) and Alan A. Doucette ${ }^{4, *}$ \\ 1 Minervagen Biotechnologies Corporation, Tucson, AZ 85704, USA; stevegriffiths@x0s0me.com \\ 2 Atlantic Cancer Research Institute, Moncton, NB E1C8X3, Canada; caissiemichelle@hotmail.com \\ 3 School of Medicine, Cardiff University, Wales, CF14 4XN, UK; claytona@cardiff.ac.uk \\ 4 Department of Chemistry, Dalhousie University, 6274 Coburg Road, Halifax, NS B3H 4R2, Canada \\ * Correspondence: alan.doucette@dal.ca; Tel.: +01-902-494-3714 \\ + Current affiliation: Royal Canadian Mounted Police, Ottawa, ON K1A 0RT Canada.
}

Received: 2 August 2017; Accepted: 2 October 2017; Published: 8 October 2017

\begin{abstract}
The complexity of human tissue fluid precludes timely identification of cancer biomarkers by immunoassay or mass spectrometry. An increasingly attractive strategy is to primarily enrich extracellular vesicles (EVs) released from cancer cells in an accelerated manner compared to normal cells. The Vn96 peptide was herein employed to recover a subset of EVs released into the media from cellular models of breast cancer. Vn96 has affinity for heat shock proteins (HSPs) decorating the surface of EVs. Reflecting their cells of origin, cancer EVs displayed discrete differences from those of normal phenotype. GELFrEE LC/MS identified an extensive proteome from all three sources of EVs, the vast majority having been previously reported in the ExoCarta database. Pathway analysis of the Vn96-affinity proteome unequivocally distinguished EVs from tumorigenic cell lines (SKBR3 and MCF-7) relative to a non-tumorigenic source (MCF-10a), particularly with regard to altered metabolic enzymes, signaling, and chaperone proteins. The protein data sets provide valuable information from material shed by cultured cells. It is probable that a vast amount of biomarker identities may be collected from established and primary cell cultures using the approaches described here.
\end{abstract}

Keywords: extracellular vesicles; breast cancer cell lines; Vn96; heat shock proteins; glycolysis; GELFrEE

\section{Introduction}

According to the American Cancer Society, breast cancer remains the most commonly diagnosed cancer among women in the United States, predicting over 250,000 new cases in 2017 and accounting for $30 \%$ of all new cancer diagnoses [1]. Breast cancer further ranks second, behind lung cancer, in terms of cancer cell death among women with $>40,000$ incidences in 2017. While five-year breast cancer survival rates approach $100 \%$ in the case of localized tumors (stage 0 or I), the prognosis for metastasized (stage IV) breast cancer is poor, with only 22\% survival at 5 years [2]. Early detection of breast cancer patients is thus crucial to improving recurrence-free survival and quality of life. Markers that distinguish invasive breast cancer phenotypes are urgently required.

Conventional screening tools, such as self-examination, mammography, diagnostic imaging (ultrasound, MRI), genetic screens (e.g., BRCA1), and tissue biopsies [3,4], collectively present vital tools for breast cancer detection. As with all tests, limits in sensitivity and specificity will miss some cancers (false-negatives); in other cases, abnormal findings associated with benign disease (false positives) will direct between $55 \%$ and $75 \%$ of women into unnecessary and potentially toxic chemotherapy [5-7]. The next generation of diagnostic and prognostic tests is continuously being 
sought. In particular, considerable effort is currently devoted to uncovering early molecular indicators released into the blood by cancer cells [8]. To this end, both DNA from circulating tumor cells [9] and microRNA released to plasma by cancer cells [10] have been reported as potential biomarkers. Differentially expressed protein biomarkers have also been observed in plasma [11]. The presence of high abundance background plasma proteins challenges the detection of low abundance proteins of interest, pointing to a need for more selective and sensitive indicators of breast cancer.

Exosomes are a subclass of extracellular vesicles (EVs), constituting membranous spheroids between 30 and 200 nM released from cells. Initially regarded as "cell dust", EVs are now unequivocally associated with various types of cancer, and carry specific profiles of proteins, nucleic acids, and lipids that serve to transmit information to other cells. Once secreted by cells into the extracellular medium, EVs retain features of the originating tissue environment [12]. EVs have also been shown to alter the metabolic activity of neighboring cells [13], and thus, may have important functional implications for tumor growth and differentiation. Not only are EVs with specific molecular payloads released by cancer cells, but they are secreted in relative higher abundance. Hence, protein profiling of cancer cell-derived exosomes has gained attention as a favorable source of protein biomarkers. Multiple approaches are available to isolate exosomes from the bulk sample. The most common approach is differential ultracentrifugation (UC); although laborious and producing a lower yield, UC remains the "gold standard" in obtaining exosomes in high purity [14]. Whilst differential centrifugation remains the laboratory method of choice [15], it is an inefficient and poorly reproducible tool that is unsuited for handling even modest numbers of clinical samples [16,17]. Access to ultracentrifugation is also limited in most clinical diagnostic laboratories, demanding robust alternative EV preparations for future translational utility. Alternative approaches, including dialysis, size exclusion chromatography, and polymer- or antibody-induced precipitation, are available [14].

In an alternative strategy, a synthetic peptide (Vn96) with high affinity for heat shock proteins (HSPs) has recently been shown to selectively isolate EVs by co-precipitation [18]. Not surprisingly, HSPs are overexpressed in cancer cells [19], where maintenance of protein homeostasis is at a premium, due to hypoxia, low $\mathrm{pH}$, and limited glucose availability. HSPs are also found in high abundance on the plasma membrane surface of exosomes [20], thus, the Vn96 pulldown represents an ideal strategy to enrich EVs shed from cancer cells. The Vn96 affinity peptide has previously been shown to recover EV material from urine, plasma, as well as cancer cell lines [21-23].

In this study, we demonstrate for the first time the utility of Vn96 in isolating breast cancer EVs for functional proteomic analysis of malignant phenotypes. We employ various breast cancer cells, including the adenocarcinoma models SKBR3, an invasive HER2 ${ }^{+}$cell and MCF-7, a luminal A cell line model. MCF-10a, a non-tumorigenic breast fibrocystic disease model, is also employed as a control. In-depth proteome analysis by LC-MS/MS, following GELFrEE fractionation of exosomal proteins, reveals numerous differentially expressed proteins, which readily distinguish the various cell lines. The proteins convey unique profiles, particularly in terms of their metabolic and chaperone activity, providing insight into the biological function of breast cancer-derived EVs and potentially pointing a strategy to uncover protein biomarkers for early breast cancer detection.

\section{Materials and Methods}

\subsection{Cell Culture and Sample Collection}

Breast cancer cell lines (SKBR3, MCF-7), along with human breast epithelial cell MCF-10a, were obtained from ATCC, and cultured according to recommended guidelines using CELLiNE Integra bioreactor flasks (Sigma, Oakville, ON, Canada), which permits addition of fresh media to layered and non-adhesive cells maintained on the opposing side of a $10 \mathrm{kDa}$ membrane. The media was supplemented with exosome-free fetal bovine serum (FBS), prepared by centrifugation of the FBS $\left(100,000 \mathrm{~g}, 2 \mathrm{~h}, 4^{\circ} \mathrm{C}\right)$ prior to use. CELLiNE media was harvested at 7-8 weeks, as optimized for the collection of exosomes [24], and immediately combined with $5 \mu \mathrm{L}$ protease cocktail inhibitor III 
per $\mathrm{mL}$ (Sigma). Remaining cells in the media were cleared by centrifugation $(1000 g, 10 \mathrm{~min})$ and microparticulate matter was further removed by centrifugation $(17,000 g, 5 \mathrm{~min})$, followed by syringe filtration through a $0.22 \mu \mathrm{m}$ membrane. Filtered solutions were stored at $4{ }^{\circ} \mathrm{C}$.

\subsection{Ultracentrifugation and Sucrose Density Gradient Fractionation}

The filtered SKBR3 cellular media was subject to $45 \mathrm{~min}$ ultracentrifugation $\left(200,000 g, 4^{\circ} \mathrm{C}\right)$. The pellet was resuspended in $100 \mu \mathrm{L}$ PBS, and overlaid onto a sucrose gradient $(0.2-2.5 \mathrm{M})$, then spun for an additional $1 \mathrm{~h}(100,000 \mathrm{~g})$. A total of 11 fractions were harvested, and the refractive index was determined. Each density fraction was split in two equal portions of $250 \mu \mathrm{L}$, with one subject to Vn96 affinity pull-down while the other served as a control.

\subsection{Vn96 Affinity Capture of EVs}

Peptide Vn96 (New England Peptide, Gardener, MA, USA) was used to precipitate vesicular material from the sucrose density fractions (Section 2.2), or from $1.9 \mathrm{~mL}$ of the microparticle-free breast cancer cell media by adding $2.5 \mu \mathrm{L}$ (or $10 \mu \mathrm{L}$ for the cell culture media) of a $10 \mu \mathrm{g} / \mu \mathrm{L}$ stock solution prepared in Extraction Buffer I of the subcellular proteome extraction kit (S-PEK, Millipore Sigma), and also containing $0.04 \%$ sodium azide. The solution was briefly vortexed, and incubated overnight at $4{ }^{\circ} \mathrm{C}$. Complexed material was pelleted by centrifugation $(3000 \mathrm{~g}, 5 \mathrm{~min}$, room temperature). The supernatant was removed, and the pelleted material was subject to two washes with 1.9 mL PBS with $10 \mu \mathrm{L}$ protease inhibitor, followed by centrifugation as above. The washed pelleted complex was visible as a translucent straw-yellow residue.

\subsection{EV Purity by Immunobloting and Transmission Electron Microscopy}

Vn96-captured EVs were resuspended by vortex in SDS-PAGE sample buffer and heating at $95{ }^{\circ} \mathrm{C}$ for $5 \mathrm{~min}$. Twenty microliter volumes were resolved on BioRad Criterion gels using XT-MES or XT-MOPS electrophoresis running buffers (BioRad, Hercules, CA, USA). Resolved proteins were transferred to either supported nitrocellulose (BioRad) or PVDF (Millipore) using standard procedures. Total protein on blots was visualized with reversible stain using either the MemCode kit (PIERCE) for nitrocellulose, or Red Alert Ponceau S (EMD Chemicals Gibbstown NJ). Membranes were blocked in PBS containing 5\% skimmed milk and 0.1\% Tween-20 for $1 \mathrm{~h}$, then incubated overnight at $4{ }^{\circ} \mathrm{C}$ in primary antibody solutions (1:1000 dilution, prepared in blocking buffer with exception of $3 \%$ milk powder). Four 10 min washes followed (blocking buffer without milk powder), then the blot was incubated for $30 \mathrm{~min}$ at room temperature in secondary antibody (1:2000 dilution, HRP-labelled antibody to the Ig consistent with primary antibody). All antibodies were obtained from Santa Cruz Biotechnology. HRP signal was produced using SuperSignal West Dura substrate (Pierce). The chemiluminescent image was captured using the ChemiGenius system (Syngene, Cambridge, UK).

For transmission electron microscopy, Vn96-captured EVs were prepared by fixation in aldehydes and osmium tetroxide [21]. The fixed pellet was embedded in epoxy resin and prepared as $50 \mu \mathrm{m}$ sections. The sections were processed and examined by standard transmission electron microscopy.

\subsection{Proteome Analysis}

The Vn96 pellet was resuspended in $250 \mu \mathrm{L}$ of SDS-PAGE sample buffer, supplemented to a final concentration of $4 \mathrm{M}$ urea and $25 \mathrm{mM}$ TCEP reducing agent (Pierce). Following heating $\left(95^{\circ} \mathrm{C}\right.$, $10 \mathrm{~min}$ ), $150 \mu \mathrm{L}$ suspended protein solutions were respectively loaded onto each of three GELFrEE cartridges (8\%, 10\%, and 12\% Tris Acetate, Expedeon, San Diego, CA, USA) and resolved according to the manufacturer's operating guidelines. With each run, 12 fractions were collected as $150 \mu \mathrm{L}$ aliquots. Together with non-fractionated Vn96 proteome pellets, a $7 \mu \mathrm{L}$ portion of each collected GELFrEE fraction was subject to SDS-PAGE and silver staining, for visualization of mass-based separation and recovery per fraction. 
Bottom up proteomic analysis of the GELFrEE-fractionated proteome first proceeded via SDS removal through chloroform-methanol-water precipitation, as described previously [25]. The resulting protein pellet was resolubilized in $20 \mu \mathrm{L}$ of $8 \mathrm{M}$ urea, then diluted to a final volume of $100 \mu \mathrm{L}$ in $50 \mathrm{mM}$ Tris buffer ( $\mathrm{pH}$ 8). Proteins were reduced following addition of $5 \mu \mathrm{L}$ of $200 \mathrm{mM}$ DTT $\left(30 \mathrm{~min}, 55^{\circ} \mathrm{C}\right.$ ), then alkylated by adding $10 \mu \mathrm{L} 200 \mathrm{mM}$ iodoacetamide (30 min, room temperature, dark). Proteins were digested overnight at $37^{\circ} \mathrm{C}$ following addition of $1 \mu \mathrm{g}$ trypsin per fraction, and the reaction was terminated with $10 \mu \mathrm{L}$ of $10 \%$ TFA.

Mass spectrometry was on an LTQ classic linear ion trap (ThermoFisher, San Jose, CA, USA), coupled to an Agilent 1200 HPLC system. Digested protein fractions were desalted by offline reversed phase HPLC with UV detection [26], loading one-third of the total volume of purified protein onto a $75 \mu \mathrm{m} \times 30 \mathrm{~cm}$ self-packed C12 column ( $3 \mu \mathrm{m}$ Jupiter beads, Phenomenex, Torrance, CA, USA). Peptides were separated using a $1 \mathrm{~h}$ linear solvent gradient from $5 \%$ acetonitrile/water $/ 0.1 \%$ formic acid to $35 \%$ acetonitrile/water $/ 0.1 \%$ formic acid at flow rate of $0.25 \mu \mathrm{L} / \mathrm{min}$. The LTQ operated in data dependent mode (MS followed by zoom scan and tandem MS of the top three ions), with $30 \mathrm{~s}$ dynamic exclusion over a mass range covering the full isotopic distribution of the peptide.

Peptide identification used the Thermo Proteome Discoverer (v. 1.3, ThermoFisher, Mississauga, Canada) software package and the SEQUEST searching algorithm. MS spectra were searched against the human UniProt database, at a mass tolerance of $1 \mathrm{Da}$, allowing static cysteine carbamidomethylation and dynamic oxidation of methionine, and up to two missed cleavages per peptide. A peptide false discovery rate of $1 \%$ by decoy database searching, and minimum of one unique peptide per protein were employed for data filtering. Relative protein abundance was obtained via spectral counting [27] with normalized peptide spectral matches (PSMs), obtained by way of a ratio of the total number of PSMs observed in the SKBR3 cell line (highest PSM total) to that of the total PSMs from the given cell line. Functional annotation was performed by Ingenuity Pathway Analysis (QIAGEN Bioinformatics, Redwood City, CA, USA).

\section{Results and Discussion}

We report a comparative proteome investigation on an in vitro model of breast cancer, examining the extracellular media from SKBR-3 (invasive cancerous cell), MCF-7 (non-invasive), and MCF-10a (immortal but non-cancerous cells). While cells adapted to grow in plastic flasks are regarded as very different from those obtained in vivo, material secreted by cancer cells into the external environment in vitro is likely to produce a similar proteomic profile, reflecting the original growth from which it was derived [28]. The Vn96 peptide was employed to selectively capture EV material released by cultured cell lines into their growth media. Vn96 targets heat shock proteins (HSPs), overexpressed on the surface of aggressive cancer cells, and by extension, their derivative vesicles [29]. The Vn96 peptide has been shown to capture exosome-like vesicles containing proteins comparable to EV preparations by traditional ultracentrifugation when analyzed by Western blot [21].

To demonstrate the specificity of Vn96 to pellet EV material, exosomes from SKBR3 were harvested through conventional ultracentrifugation with separation into characteristic flotation zones by sucrose density fractionation. As shown in Figure 1, the exosomal marker proteins TSG101 and Alix were isolated in the fractions from 1.15 to $1.23 \mathrm{~g} / \mathrm{mL}$. Moreover, while these marker proteins remain suspended in the supernatant (SN) following low speed centrifugation, the addition of Vn96 resulted in recovery of exosomal markers in the pellet $(\mathrm{P})$ of the low speed spin. These observations demonstrate the capacity of Vn96 to concentrate proteins associated with vesicular material. 

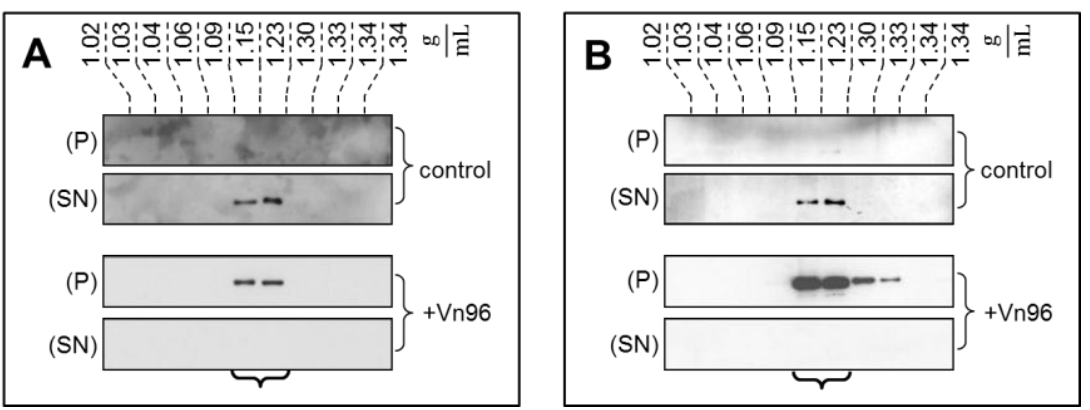

Figure 1. Western blot analysis of fractions recovered from sucrose density gradient isolation of SKBR3 extracellular vesicles (EVs) reveals the presence of exosomal marker proteins TSG101 (A) and Alix (B). These proteins remain in the supernatant in the control sample following low speed centrifugation. With addition of Vn96, the low speed spin recovers the same proteins in the pelleted material.

The Vn96 peptide was next employed to directly recover EV materials from filtered bioreactor cell culture media. When observed by TEM Figure 2, material pulled down by Vn96 generally consisted of bilayer orb structures between 30 and $50 \mathrm{~nm}$ in diameter, with electron dense centers. Such features were also evident in the MCF-10a cell line, indicative that HSP-decorated vesicles are also released by these cells. In recent years, the term "small EVs" has been used as an alternative to exosomes [30]. Vn96 may capture a subset of small EVs, as defined by surface accessorization of HSPs.
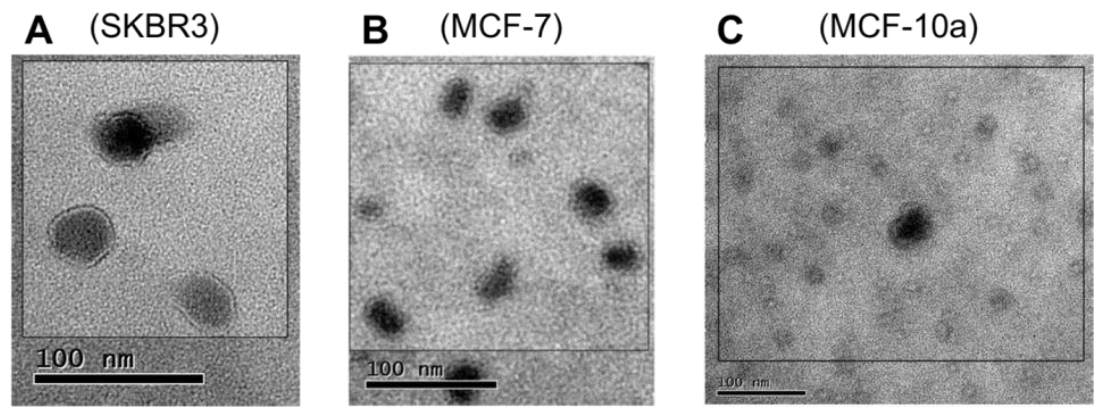

Figure 2. TEM images showing the distribution of microvesicular bodies recovered from the extracellular media by precipitation with Vn96 peptide of (A) SKBR3; (B) MCF-7; (C) MCF-10a. The size distribution of the particles is consistent with small extracellular vesicles.

Electrophoretic profiling of Vn96 pull-downs yielded robust total protein profiles (e.g., from SKBR3, Figure 3A lane 1). Replacement of Vn96 with a random peptide (SW) yielded faint profiles likely to be aggregates of albumin and immunoglobulin from culture medium (Figure 3A, lane 2). The heat shock proteins (HSP70, HSP90) targeted by Vn96 were depleted from the medium and exclusively recovered in the low centrifuge speed pellet. Employing a random peptide (SW), or scrambled amino acid sequence of Vn96 did not pellet these proteins (Figure 3B). Western blots of EV material also identified PKM2, receptor kinase HER2, membrane protein TRPV6, and fatty acid synthase; none of which were recovered using the null peptide (Figure 3B). The stability of EVs isolated by Vn96 from SKBR3 is also evident in Figure 3C, which employs various commercial detergent washes (components of Millipore's subcellular proteome extraction kit, S-PEK). As seen in lanes 1 and 2 of Figure 3C, neither cytosolic Extraction Buffer I (EB1), which contains the mild detergent digitonin, nor membrane and organelle Extraction Buffer II (EB2), containing Triton X-100, would solubilize the EV marker proteins from the Vn96 pellet. Similar results are obtained from the other cell lines. Though EV marker proteins are retained following EB1 and EB2 washes, weakly associated proteins are liberated from the EV pellet by these buffers (see Supplementary Figure S1). These findings permit incorporation of stringent washes to further purify the EV fraction recovered 
in the Vn96 pellet. Immunoblot analysis on material recovered from the non-transformed MCF-10a cell culture media, as well as for MCF-7, with the breast cancer exosomal marker CD24 [31], illustrate that some, but not all, CD24 is released into the supernatant following incubation of the pellet with EB II (results not shown). Thus, we subsequently chose a PBS washing protocol, also under reducing conditions (25 mM TCEP), to achieve a balance of yield and purity. To fully solubilize EV proteins (lane 3 of Figure 3C), the pellet is boiled in SDS gel-loading buffer, supplemented with $4 \mathrm{M}$ urea (USB). As a consequence, MS analysis demands an SDS-compatible proteomics workflow.
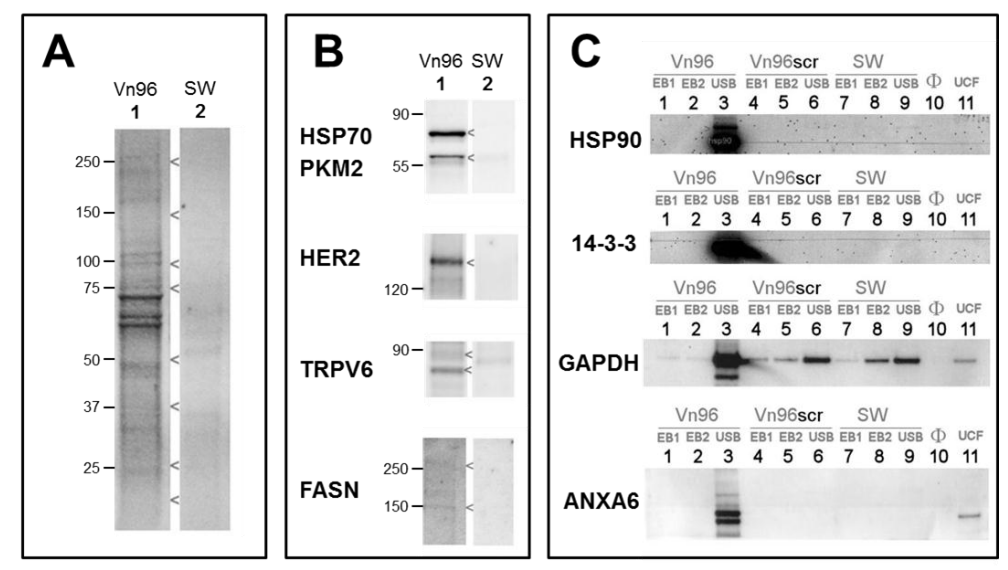

Figure 3. Immunoblots probing for exosomal marker proteins in the Vn96 pellets isolated from SKBR3 cell culture media. (A) A random peptide (SW) precipitates few proteins from the extracellular media, as evident from a total protein stain; (B) Marker proteins are observed in the immunoblots of the Vn96 pulldown following solubilization in SDS-containing buffer (USB); (C) Extracting the Vn96 pellet with mild detergent buffers, EB1 \& EB2, from Millipore's subcellular proteome extraction kit, S-PEK, will not release proteins from the Vn96 pellet, permitting incorporation of a wash step to improve purity. As controls, equivalent volumes of culture medium were processed by ultracentrifugation (UCF), the pellet was resuspended in electrophoresis buffer and loaded directly (Lane 11).

Mass spectrometry detection followed GELFrEE fractionation of the solubilized EV proteomes. GELFrEE enables recovery of proteins in an SDS-containing buffer, with separation according to molecular weight. SDS depletion via organic solvent precipitation permits LC/MS of trypsin-digested proteins. As demonstrated in Figure 4A, a higher abundance of EV proteins was recovered from the SKBR3 and MCF-7 cell lines, relative to the non-cancerous MCF-10a, in support of the theory that aggressive cancer cells will overexpress EV materials. The decreased abundance of proteins recovered by Vn96 from the MCF-10a cell media may also reflect a lower number of Vn96 binding opportunities, due to lack of surface expressed HSP/chaperones. Nonetheless, it is clear that a greater concentration of proteins is recovered from the tumorigenic cell lines. GELFrEE resolved the proteins over a mass range extending to $\sim 100 \mathrm{kDa}$ Figure $4 \mathrm{~B}$, isolating proteins in discrete fractions according to molecular weight (Figure 4C). A detailed listing of the identified proteins and peptides from each of the three cell lines are provided as supplementary files (Tables S1-S3). 


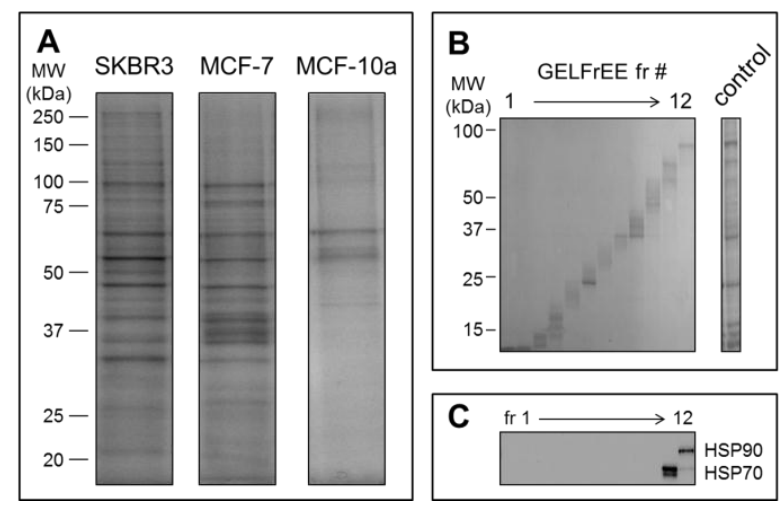

Figure 4. (A) SDS-PAGE of proteins recovered from Vn96 pellets reveal significantly more proteins from the cancerous cell lines SKBR3 and MCF-7 relative to the non-cancerous control MCF-10a; (B) GELFrEE fractionation resolves proteins according to molecular weight. Shown is the separation of SKBR-3 proteins from the EV pellet as obtained on the $8 \%$ (high molecular weight) gel cartridge; (C) Immunoblot of the identically resolved proteome as above, showing resolution of heat shock proteins (HSP70 and HSP90).

As summarized in the Venn diagrams of Figure 5, some $\sim 300$ to 400 unique proteins were identified from each cell type (minimum 2 peptides per protein). The largest number of identified proteins (392) was seen from the most aggressive cancer cell line (SKBR3), and might be a reflection of the increased prominence of HSPs expressed on the EV surface. Considering all three samples and technical replicates (three GELFrEE runs per sample type), MS collectively identified 647 unique proteins across the various cell lines. Despite marked differences in protein concentration across the three cell lines, similar numbers of proteins were identified through MS. This may reflect on the limitations of an MS platform which favors detection of the most abundant components. While greater differences are reflected at the peptide level Figure 5, comparative analysis of the discrete proteomes is best presented through changes in the protein abundance. Here, spectral counting is employed as a means of assessing relative protein abundance across the three cell types. In total, we obtained 7400 peptide spectral matches (PSMs) from SKBR3; 4584 PSMs from MCF-7; and 2381 PSMs from MCF-10a, being indicative of the greater concentration of $\mathrm{EV}$ proteins recovered in the most invasive phenotype. Supplementary Table S4 details a full comparative assessment of the spectral matches observed per protein across the three cell lines. Supplementary Table S5 compares the identified proteins to the ExoCarta protein database [32], indicating that the majority of proteins detected (509 of 575 gene products) were previously found to be associated with exosomal material.

A

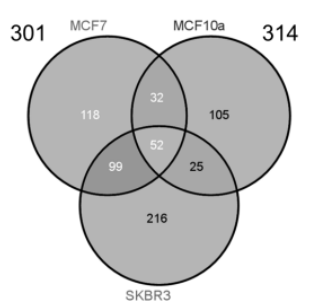

392

PROTEINS
B

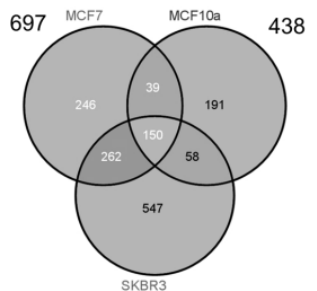

1017

PEPTIDES

Figure 5. Venn diagrams summarize (A) the proteins and (B) peptides identified by mass spectrometry from each of the three cell lines. Detailed listings of identified proteins are provided as supplemental files. 
Reflecting the origin of EVs as they are produced by the cell, and considering the cellular distribution of proteins identified from the EV fractions (Supplementary Figure S2), it is not surprising that several of the identified proteins were associated with the membrane $(19 \%)$, or cellular surface $(12 \%)$. The large number of extracellular proteins is reflective of the heat shock proteins along with other proteins normally released by cells. Tables 1-3 summarize the top 25 proteins (excluding probable contaminants), as categorized according to primary function (metabolism; chaperone and protein binding; skeletal and assembly).

Table 1. Top 25 proteins identified in SKBR3 EV fraction, excluding probable contaminants.

\begin{tabular}{|c|c|c|c|c|}
\hline \multicolumn{5}{|c|}{ SKBR3 } \\
\hline Protein Name & ID & Unique Peptides & PSMs & Function \\
\hline Enolase & P06733 & 13 & 197 & metabolism \\
\hline Fatty acid synthase & P49327 & 20 & 139 & metabolism \\
\hline Phosphoglycerate kinase & P00558 & 11 & 82 & metabolism \\
\hline Fructose bisphosphatase 1 & P09467 & 11 & 70 & metabolism \\
\hline GAPDH & E7EUT5 & 7 & 64 & metabolism \\
\hline Malate dehydrogenase & E9PDB2 & 10 & 59 & metabolism \\
\hline L-lactate dehydrogenase & P00338 & 8 & 50 & metabolism \\
\hline Aldehyde dehydrogenase & F8W0A9 & 8 & 48 & metabolism \\
\hline Aldolase & H3BPS8 & 6 & 33 & metabolism \\
\hline Triosephosphate isomerase & P60174 & 6 & 31 & metabolism \\
\hline Glucosidase 2 subunit beta & P14314 & 6 & 28 & metabolism \\
\hline Selenium-binding protein 1 & Q13228 & 6 & 106 & binding \\
\hline $60 \mathrm{kDa}$ heat shock protein & P10809 & 8 & 101 & binding \\
\hline Protein disulfide-isomerase & I3L2P8 & 9 & 63 & binding \\
\hline 14-3-3 protein zeta/delta & P63104 & 6 & 49 & binding \\
\hline Lamin $\mathrm{A} / \mathrm{C}$ & Q6UYC3 & 6 & 49 & binding \\
\hline Tumor protein D52 & D3YTI0 & 7 & 44 & binding \\
\hline $14-3-3$ protein epsilon & P62258 & 8 & 38 & binding \\
\hline TER ATPase & P55072 & 6 & 25 & binding \\
\hline Cytokeratin 19 & P08727 & 18 & 635 & assembly \\
\hline Cytokeratin 8 & P05787 & 20 & 350 & assembly \\
\hline Cytokeratin 18 & F8VZY9 & 8 & 112 & assembly \\
\hline Cytokeratin 16 & P08779 & 7 & 109 & assembly \\
\hline alpha-Actinin-4 & O43707 & 11 & 72 & assembly \\
\hline Myosin-9 & P35579 & 11 & 26 & assembly \\
\hline
\end{tabular}

Table 2. Top 25 proteins identified in MCF-7 EV fraction, excluding probable contaminants.

\begin{tabular}{|c|c|c|c|c|}
\hline \multicolumn{5}{|c|}{ MCF-7 } \\
\hline Protein Name & ID & Unique Peptides & PSMs & Function \\
\hline Enolase & P06733 & 9 & 103 & metabolism \\
\hline Aldolase & H3BQN4 & 7 & 62 & metabolism \\
\hline Fructose bisphosphatase 1 & P09467 & 11 & 59 & metabolism \\
\hline Triosephosphate isomerase & P60174 & 8 & 49 & metabolism \\
\hline Pyruvate kinase & P14618 & 7 & 45 & metabolism \\
\hline Phosphoglycerate kinase & B7Z7A9 & 8 & 38 & metabolism \\
\hline GAPDH & E7EUT5 & 6 & 27 & metabolism \\
\hline Tryptophan-tRNA ligase & P23381 & 8 & 23 & metabolism \\
\hline Cathepsin D & P07339 & 5 & 20 & metabolism \\
\hline Kynureninase & Q16719 & 6 & 15 & metabolism \\
\hline TER ATPase & P55072 & 5 & 15 & metabolism \\
\hline Lactoferroxin-C & B7Z4X2 & 9 & 14 & metabolism \\
\hline Hexokinase-1 & B4DG62 & 7 & 13 & metabolism \\
\hline $14-3-3$ protein zeta/delta & P63104 & 7 & 83 & binding \\
\hline 14-3-3 protein epsilon & P62258 & 9 & 63 & binding \\
\hline Selenium-binding protein 1 & Q13228 & 6 & 38 & binding \\
\hline HSP 90-a & P07900 & 5 & 29 & binding \\
\hline Agrin & O00468 & 5 & 25 & binding \\
\hline Protein SET & Q01105 & 5 & 21 & binding \\
\hline Cytokeratin 8 & P05787 & 23 & 557 & assembly \\
\hline Cytokeratin 19 & P08727 & 11 & 241 & assembly \\
\hline Cytokeratin 18 & P05783 & 13 & 197 & assembly \\
\hline Actin, cytoplasmic 1 & P60709 & 9 & 103 & assembly \\
\hline Filamin A & A6NDY9 & 7 & 38 & assembly \\
\hline Lamin A/C & Q6UYC3 & 6 & 38 & assembly \\
\hline
\end{tabular}


Table 3. Top 25 proteins identified in MCF-10a EV fraction, excluding probable contaminants.

\begin{tabular}{|c|c|c|c|c|}
\hline \multicolumn{5}{|c|}{ MCF-10a } \\
\hline Protein Name & ID & Unique Peptides & PSMs & Function \\
\hline Enolase & P06733 & 5 & 29 & metabolism \\
\hline GAPDH & E7EUT5 & 4 & 15 & metabolism \\
\hline Matrix metalloproteinase-2 & B4DWH3 & 4 & 7 & metabolism \\
\hline Tripeptidyl-peptidase 1 & O14773 & 3 & 7 & metabolism \\
\hline Cathepsin D & P07339 & 3 & 5 & metabolism \\
\hline Complement component $1 \mathrm{r}$ & H0YFH3 & 3 & 4 & metabolism \\
\hline Protein disulfide-isomerase & P13667 & 3 & 4 & metabolism \\
\hline Anastellin & F8W7G7 & 12 & 63 & binding \\
\hline Periostin & F5H628 & 4 & 29 & binding \\
\hline Serpin B5 & P36952 & 4 & 15 & binding \\
\hline TGF- $\beta$-induced protein ig-h3 & G8JLA8 & 6 & 14 & binding \\
\hline Actin, cytoplasmic 1 & F5GYT4 & 4 & 70 & assembly \\
\hline Laminin subunit gamma-2 & F5H430 & 4 & 53 & assembly \\
\hline Filamin A & A6NDY9 & 6 & 39 & assembly \\
\hline Cytokeratin 8 & P05787 & 4 & 31 & assembly \\
\hline Alpha-actinin-4 & O43707 & 6 & 23 & assembly \\
\hline Thrombospondin-1 & P07996 & 5 & 20 & assembly \\
\hline Laminin subunit gamma-1 & P11047 & 3 & 16 & assembly \\
\hline alpha-Actinin-1 & H9KV75 & 5 & 13 & assembly \\
\hline Myosin-9 & P35579 & 4 & 13 & assembly \\
\hline Tropomyosin a- 1 chain & H0YKP3 & 3 & 10 & assembly \\
\hline Agrin & O00468 & 5 & 9 & assembly \\
\hline Filamin-B & O75369 & 4 & 7 & assembly \\
\hline Desmoplakin & P15924 & 3 & 4 & assembly \\
\hline Laminin subunit alpha-5 & O15230 & 3 & 4 & assembly \\
\hline
\end{tabular}

Multiple cytoskeleton proteins (keratins, actin, myosin, etc.) dominated the list of identified proteins (see Supplementary Tables S1-S3). Keratins are frequently encountered as unavoidable contaminant proteins during sample collection and processing. As such, suspected keratin contaminants (keratin type 1, 2, 5, 9, 14, 16) were among the identified proteins. These proteins exhibit minimal statistical difference in peptide spectral counts among the three cell types. However, such contaminants are easily distinguishable from bona fide cancer markers, such as cytokeratin 8 , 18 , and 19. These molecules are found at the surface of cancer cells, and are thus either incorporated as bystanders, or as part of the EV assembly and embarkation process. CK8 and CK18 are well documented as secreted cancer biomarkers, and may be detected in serum of patients with breast cancer receiving chemotherapy [33]. These markers were shown to resist extraction by wash buffers EB1 and EB2 (Supplementary Figure S1), and are thus likely to be strongly associated or embedded within the extracellular vesicles. CK19 has been suggested to be likely involved in driving the more aggressive tumor proliferation, invasion, and metastasis associated with HER-2/neu-positive tumors [34]. By their PSMs, each of these marker proteins were highly elevated in the cancer cell lines relative to MCF-10a (Tables 1-3). Thus, these proteins are included in the lists of relevant EV components.

Considering the full list of proteins collectively identified in the EV material, a broad range of biological function is conveyed (Supplementary Figure S2). The largest group of proteins identified $(18 \%)$ were associated with metabolic activity. The chaperone/binding proteins were also prominent among the identified groups. A preliminary comparison of the molecular pathways associated with the identified proteins is seen through Ingenuity Pathway Analysis (IPA), for which the top 12 pathways of each cell type are depicted in Supplementary Figure S3. The most distinguishing feature was the glycolysis/gluconeogenesis and the pentose phosphate pathways, represented at the top of IPA pathways represented in SKBR3 (second and fourth for MCF-7). By sharp contrast, metabolic enzymes constitutive of these pathways were essentially absent from MCF-10a.

Cancers are dominated by metabolic pathways that vary from normative physiology with emphasis on accelerated uptake of glucose and glutamine, aerobic glycolysis, decreased mitochondrial activity, and enhanced lipogenesis. Table 4 provides a quantitative comparison of proteins involved in metabolic pathways. Perhaps the most well-known characteristic, the Warburg effect [35], refers 
to the avid consumption of glucose for direction into a glycolytic pathway with the accumulation of lactate, rather than incorporation of pyruvate into the tricarboxylic acid (TCA) cycle for oxidative phosphorylation. Nine of the ten canonical enzymes of glycolysis were represented in the Vn96 captured EVs of both SKBR3 and MCF-7, though only five were observed in MCF-10a. Some elements were exclusively found in the invasive and non-invasive VNEs, such as isoforms of pyruvate kinase and lactate dehydrogenase. Lactate dehydrogenase is perhaps the most widely recognized secreted enzyme of glycolysis contributing to the acidification paradigm of the Warburg effect [36]. Metabolism is thus closely linked to cancer progression, because the ability for a cell to proliferate is dependent upon the availability of nutrients to build new cells. Glycolytic enzymes also protect cancer cells from stress by inhibiting apoptosis, and correlate well with resistance to radio- and chemotherapy $[37,38]$. Early diversions are promoted toward the pentose phosphate pathway as the means to generate nucleotide and amino acids. Of relevance was the detection of phosphogluconate dehydrogenase in higher abundance for the cancerous cell lines.

Table 4. Summary of proteins involved in metabolic pathways and detected in EV pellets for each cell lines.

\begin{tabular}{|c|c|c|c|c|}
\hline \multirow{2}{*}{ Protein Description } & \multirow{2}{*}{ Process } & \multicolumn{3}{|c|}{ Protein Spectral Hits (PSMs) } \\
\hline & & SKBR3 & MCF7 & MCF10 \\
\hline Hexokinase 1 & Glycolysis/Gneo & 1 & 13 & 0 \\
\hline Glucose-6-phosphate isomerase & Glycolysis/Gneo & 1 & 1 & 0 \\
\hline Phosphofructokinase & Glycolysis/Gneo & 0 & 0 & 0 \\
\hline Aldolase (fructose 1,6-bisphosphatase) & Glycolysis/Gneo & 138 & 176 & 12 \\
\hline Triosephosphate isomerase 1 & Glycolysis/Gneo & 31 & 49 & 2 \\
\hline GAPDH & Glycolysis/Gneo & 64 & 27 & 15 \\
\hline Phosphoglycerate kinase & Glycolysis/Gneo & 82 & 38 & 5 \\
\hline Phosphoglycerate mutase & Glycolysis/Gneo & 7 & 3 & 0 \\
\hline Enolase & Glycolysis/Gneo & 197 & 123 & 29 \\
\hline Pyruvate kinase & Glycolysis/Gneo & 17 & 45 & 0 \\
\hline Fatty Acid Synthase & Lipogenesis & 139 & 1 & 0 \\
\hline Tumor Protein D52 & Lipid storage & 44 & 0 & 0 \\
\hline Lactate dehydrogenase A & Glycolysis/Gneo & 50 & 40 & 0 \\
\hline Lactate dehydrogenase B & Glycolysis/Gneo & 11 & 0 & 0 \\
\hline 6-phosphogluconate dehydrogenase & Pentose Phosphate & 27 & 22 & 7 \\
\hline Isocitrate dehydrogenase & TCA & 29 & 14 & 0 \\
\hline
\end{tabular}

Beyond glycolysis, the provision of raw materials into peripheral biosynthetic pathways is crucial to cancer survival and colonization of areas distal to the primary tumor [39]. For example, glycolysis channels raw material into lipid biosynthesis for membrane expansion and vesicle production [40,41]. Lipogenesis, required for membrane expansion and vesicle production, and typical of the aggressive cancer, would benefit from the donation of precursors. As seen in Table 4, a high proportion of peptides originate from fatty acid synthase (FASN) in the invasive SKBR3. Similarly, tumor protein D52 was also exclusively observed in SKBR3, being implicated in increased capacity for storing lipid typical of invasive cancer cells [42]. The significance of FASN abundance in an invasive phenotype is likely associated with the promotion of membrane biogenesis. FASN is frequently associated with invasive cancer, and has been proposed as a therapeutic target [43]. It is normally expressed in low levels when dietary sources are sufficient. However, FASN expression and activity in cancer cells can be very high, and becomes associated with lipid rafts following cell signaling events [44]. Serum levels of FASN have been found extracellularly in breast cancer [45], and are predictive of colorectal cancer stage [46]. FASN has previously been found in exosomes from multiple cancer cells [32]. Accordingly, it is possible that proportional representation of FASN in exosomes is a prospective biomarker of invasive phenotype [47].

As ligands for the Vn96 affinity peptide, individual canonical heat shock proteins are listed in Table 5. HSP60 was the most abundantly represented heat shock protein among the three cell lines, and most highly expressed in SKBR3. HSP60 is a known surface-displayed molecule, secreted by cancer cells, and an important marker of cancer-derived exosomes [48]. Isoforms of HSP90 
were more extensively represented in SKBR3, though also observed in the non-cancerous cell line MCF7. HSP90-alpha constitutes the extracellular isoform, and is particularly characteristic of invasive cancer [49]. Although location of HSP90 isoforms was not determined, this family of proteins is frequently found on the cell surface of cancer cells, and by extension, on derivative vesicles [50]. HSP90 is imperative as a stabilizing chaperone of a broad range of aberrantly overactive receptors and kinases imperative to cancer. Transient HSP-multi protein complexes, coined as the "epichaperome" and found in high prevalence on numerous cancers, have been shown to play important roles in facilitating cell regulation and survival [51]. Thus, while smaller chaperones, HSP10 or HSP27, were observed in higher abundance in the cancerous cell lines, it is unknown if these are independently capable of engaging Vn96. However, HSP10 and 27 have been implicated in multifunctional chaperone networks in invasive breast cancer [52]. HSP chaperone complexes not only present biomarkers for cancer diagnostics, but have been identified as targets for drug therapy [51].

Table 5. Canonical heat shock proteins identified in the EV fractions.

\begin{tabular}{ccccc}
\hline \multirow{2}{*}{ Protein Name } & SwissProt Accession Number & \multicolumn{3}{c}{ Peptide Spectral Matches } \\
\cline { 3 - 5 } & & SKBR3 & MCF7 & MCF10a \\
\hline HSP10 & [B8ZZL8] & 7 & 7 & 0 \\
HSP60 & {$[$ [P10809] } & 101 & 9 & 0 \\
HSP70-1A/1B & [E9PKE3], [E9PQQ4] & 3 & 7 & 1 \\
HSP71 & [P04792], [B4DL87] & 32 & 5 & 2 \\
HSP27 & P11021 & 57 & 53 & 0 \\
GRP78 (Hsp70-5) & {$[$ [P07900] } & 77 & 16 & 39 \\
HSP90-alpha & {$[$ P08238] } & 70 & 29 & 0 \\
HSP90-beta & {$[$ P14625], [E9PEX3] } & 12 & 0 & 41 \\
GRP94 (Hsp90-B1) & SUM: & 347 & 4 & 6 \\
& & & 126 & 87 \\
\hline
\end{tabular}

The functional elements of a metastatic cascade reside in secreted proteins invested in HSP-decorated EVs. Cumulatively, these proteins enable cells to detach, invade tissue, and access circulation, while buffering against toxicity. Proteome profiling of the EV materials from malignant vs non-invasive phenotypes reveals multiple features conducive to malignancy, some of which have only been appreciated in the last year. A short selection is provided in Table 6. The role of these proteins in cancer progression is described in the table with reference to literature. For example, protein disulfide isomerases are multifunctional chaperones instrumental in the breakage and rearrangement of disulfide bonds of extracellular matrix proteins, being required for detachment, extravasation, and intravasation at secondary sites, particularly with regard to cellular matrix remodeling. Other proteins may protect or preserve aspects crucial to metabolism (e.g., selenium-binding protein 1), while other proteins may promote expression of specific proteins or enable function to maintain the malignant phenotype (14-3-3 zeta). The Vn96 protocol to isolate EV materials uncovers multiple distinguishing protein features, which collectively constitute candidate biomarkers of breast cancer.

Table 6. Selected EV pulldown proteins conducive to malignancy, listing peptide spectral matches.

\begin{tabular}{|c|c|c|c|c|c|c|}
\hline Protein Description & Accession & SKBR3 & MCF7 & MCF10 & Function & Ref. \\
\hline Selenium-binding protein 1 & [Q13228] & 106 & 38 & 0 & Detox & [53] \\
\hline PDIA1 (P4HB) & [I3L2P8] & 63 & 0 & 0 & Invasion & [54] \\
\hline PDIA3 (ERP57, GRP58) & [H7BZJ3] & 52 & 6 & 1 & Invasion & [55] \\
\hline Aldehyde dehydrogenase 1 & [F8W0A9] & 48 & 0 & 0 & Detox & [56] \\
\hline $14-3-3$ zeta/delta $\zeta$ & [P63104] & 49 & 82 & 0 & Enabler & [57] \\
\hline Sushi Domain Containing D2 & [Q9UGT4] & 48 & 0 & 0 & Invasion & [58] \\
\hline Acylamino-acid-releasing & [P13798] & 41 & 14 & 0 & Detox & [59] \\
\hline Calcyphosin & [Q13938] & 41 & 0 & 0 & Proliferation & [60] \\
\hline SS DNA-binding & [Q04837] & 38 & 0 & 0 & Resistance & [61] \\
\hline Galectin-3-binding & [Q08380] & 36 & 0 & 0 & Invasion & [62] \\
\hline Calreticulin & [P27797] & 33 & 0 & 0 & Protection & [63] \\
\hline 60S ribosomal P2 & [P05387] & 31 & 0 & 0 & Enabler & [64] \\
\hline Glucosidase 2 beta $(80-\mathrm{KH})$ & [P14314] & 28 & 2 & 7 & Invasion & [65] \\
\hline
\end{tabular}


Previous investigations on breast cancer cell lines [66], or of their secreted exosomes [67], have highlighted proteomic profiles indicative of cancer cell proliferation and mobility, which was also apparent from our study. Our observations also corroborate a proteomic study that identified proteins involved in metabolic and detoxification pathways as highly expressed in HER-2/neu-positive breast cancer [68].

\section{Conclusions}

Vesicles were recovered from extracellular media by peptides with affinity to heat shock proteins, which are abundant on cancer cell surface and derivative vesicles or exosomes. Extracellular vesicles (EVs) were subject to GELFrEE fractionation and proteome analysis via bottom up liquid chromatography mass spectrometry (LC/MS). Enzymes typical of altered metabolic pathways were abundantly represented in EVs from cancer cells. Vesicle-associated proteins from the most invasive phenotype, SKBR3, included most of the canonical enzymes of glycolysis and gluconeogenesis. In contrast, the same proteins were of limited representation or absent in EVs from non-transformed MCF-10a, while MCF-7 yielded an intermediate representation. These observations indicate that the collection of extracellular vesicles from different cancer cell phenotypes may provide insight into the importance of individual enzymes in cancer progression, and further, that the vesicles shed from cancer cells serve as surrogates for profiling abundance of altered metabolic enzymes.

Supplementary Materials: The following are available online at www.mdpi.com/2227-7382/5/4/25/s1, Figure S1: Washes of Vn96 pellet, Figure S2: Gene Ontology, Figure S3: Ingenuity Pathway Analysis, Table S1: Proteins from SKBR3, Table S2: Proteins from MCF-7, Table S3: Proteins from MCF-10a, Table S4: Proteins in ExoCarta database, Table S5: Comparative quantitative analysis by peptide spectral counting.

Acknowledgments: The authors acknowledge Susan Belfry, University of New Brunswick, Fredericton, for processing and examining all transmission electron microscopy images, as well as Fang Liu, Department of Chemistry, Dalhousie University, for performing the proteome digestion and MS analysis. Felix Royo and Juan Falcón-Pérez, CIC bioGUNE, Bizkaia Spain, are acknowledged for their contributions towards Ingenuity Pathway Analysis. This work was made possible by grants from the Beatrice Hunter Cancer Research Institute as well as the Breast Cancer Society of Canada-Queen Elizabeth II Foundation Award.

Author Contributions: S.G. conceived of and designed the Vn96 peptide. M.C. maintained cell lines, recovered all protein samples, performed all qualitative electrophoretic separations and blotting image development. A.C. performed the sucrose density recovery of exosomes and Vn96 assessment of resulting fractions. S.G. and A.D. conceived and designed the experiments and wrote the paper.

Conflicts of Interest: The authors declare no conflict of interest.

\section{References}

1. Siegel, R.L.; Miller, K.D.; Jemal, A. Cancer statistics, 2017. CA Cancer J. Clin. 2017, 67, 7-30. [CrossRef] [PubMed]

2. Americal Cancer Society. Available online: https://www.cancer.org/cancer/breast-cancer/understandinga-breast-cancer-diagnosis/breast-cancer-survival-rates.html (accessed on 25 July 2017).

3. Lehman, C.D.; Isaacs, C.; Schnall, M.D.; Pisano, E.D.; Ascher, S.M.; Weatherall, P.T.; Bluemke, D.A.; Owen, D.J.; Marcom, P.K.; Armstrong, D.K.; et al. Cancer yield of mammography, MR, and US in high-risk women: Prospective multi-institution breast cancer screening study. Radiology 2007, 244, 381-388. [CrossRef] [PubMed]

4. $\quad$ Berg, W.A.; Zhang, Z.; Lehrer, D.; Jong, R.A.; Pisano, E.D.; Barr, R.G.; Böhm-Vélez, M.; Mahoney, M.C.; Evans, W.P., 3rd; Larsen, L.H.; et al. Detection of breast cancer with addition of annual screening ultrasound or a single screening MRI to mammography in women with elevated breast cancer risk. JAMA 2012, 307, 1394-1404. [CrossRef] [PubMed]

5. Elmore, J.G.; Barton, M.B.; Moceri, V.M.; Polk, S.; Arena, P.J.; Fletcher, S.W. Ten-year risk of false positive screening mammograms and clinical breast examinations. N. Engl. J. Med. 1998, 338, 1089-1096. [CrossRef] [PubMed]

6. Gøtzsche, P.C.; Jørgensen, K.J.; Maehlen, J.; Zahl, P.-H. Estimation of lead time and overdiagnosis in breast cancer screening. Br. J. Cancer 2009, 100, 219. [CrossRef] [PubMed] 
7. Keen, J.D.; Keen, J.E. What is the point: Will screening mammography save my life? BMC Med. Inform. Decis. Mak. 2009, 9, 18. [CrossRef] [PubMed]

8. Hanash, S.M.; Pitteri, S.J.; Faca, V.M. Mining the plasma proteome for cancer biomarkers. Nature 2008, 452, 571-579. [CrossRef] [PubMed]

9. Dawson, S.J.; Tsui, D.W.; Murtaza, M.; Biggs, H.; Rueda, O.M.; Chin, S.F.; Dunning, M.J.; Gale, D.; Forshew, T.; Mahler-Araujo, B. Analysis of circulating tumor DNA to monitor metastatic breast cancer. N. Engl. J. Med. 2013, 368, 1199-1209. [CrossRef] [PubMed]

10. Heneghan, H.M.; Miller, N.; Lowery, A.J.; Sweeney, K.J.; Newell, J.; Kerin, M.J. Circulating microRNAs as novel minimally invasive biomarkers for breast cancer. Ann. Surg. 2010, 251, 499-505. [CrossRef] [PubMed]

11. Meng, R.; Gormley, M.; Bhat, V.B.; Rosenberg, A.; Quong, A.A. Low abundance protein enrichment for discovery of candidate plasma protein biomarkers for early detection of breast cancer. J. Proteom. 2011, 75, 366-374. [CrossRef] [PubMed]

12. Ziegler, Y.S.; Moresco, J.J.; Yates, J.R.; Nardulli, A.M. Integration of breast cancer secretomes with clinical data elucidates potential serum markers for disease detection, diagnosis, and prognosis. PLoS ONE 2016, 11, e0158296. [CrossRef] [PubMed]

13. Zhao, H.; Yang, L.; Baddour, J.; Achreja, A.; Bernard, V.; Moss, T.; Marini, J.C.; Tudawe, T.; Seviour, E.G.; San Lucas, F.A.; et al. Tumor microenvironment derived exosomes pleiotropically modulate cancer cell metabolism. Elife 2016, 5, e10250. [CrossRef] [PubMed]

14. Abramowicz, A.; Widlak, P.; Pietrowska, M. Proteomic analysis of exosomal cargo: The challenge of high purity vesicle isolation. Mol. Biosyst. 2016, 12, 1407-1419. [CrossRef] [PubMed]

15. Théry, C.; Clayton, A.; Amigorena, S.; Raposo, G. Isolation and characterization of exosomes from cell culture supernatants. Curr. Protoc. Cell Biol. 2006. [CrossRef]

16. Mitchell, P.J.; Welton, J.; Staffurth, J.; Court, J.; Mason, M.D.; Tabi, Z.; Clayton, A. Can urinary exosomes act as treatment response markers in prostate cancer? J. Transl. Med. 2009, 7, 4. [CrossRef] [PubMed]

17. Taylor, D.D.; Zacharias, W.; Gercel-Taylor, C. Exosome isolation for proteomic analyses and RNA profiling. In Serum/Plasma Proteomics: Methods and Protocols; Simpson, R.J., Greening, D.W., Eds.; Humana Press: Totowa, NJ, USA, 2011; pp. 235-246, ISBN 978-1-61779-068-3.

18. Griffiths, S.G.; Lewis, S.E. Polypeptides with affinity for heat shock proteins (HSPs) and HSP associated complexes (HACS) and their use in diagnosis and therapy. U.S. Patent 8,956,878, 17 February 2015.

19. Melendez, K.; Wallen, E.S.; Edwards, B.S.; Mobarak, C.D.; Bear, D.G.; Moseley, P.L. Heat shock protein 70 and glycoprotein 96 are differentially expressed on the surface of malignant and nonmalignant breast cells. Cell Stress Chaperones 2006, 11, 334-342. [CrossRef] [PubMed]

20. Santos, T.G.; Martins, V.R.; Hajj, G.N.M. Unconventional secretion of heat shock proteins in cancer. Int. J. Mol. Sci. 2017, 18, 946. [CrossRef] [PubMed]

21. Ghosh, A.; Davey, M.; Chute, I.C.; Griffiths, S.G.; Lewis, S.; Chacko, S.; Barnett, D.; Crapoulet, N.; Fournier, S.; Joy, A.; et al. Rapid isolation of extracellular vesicles from cell culture and biological fluids using a synthetic peptide with specific affinity for heat shock proteins. PLoS ONE 2014, 9, e110443. [CrossRef] [PubMed]

22. Bijnsdorp, I.V.; Maxouri, O.; Kardar, A.; Schelfhorst, T.; Piersma, S.R.; Pham, T.V.; Vis, A.; van Moorselaar, R.J.; Jimenez, C.R. Feasibility of urinary extracellular vesicle proteome profiling using a robust and simple, clinically applicable isolation method. J. Extracell. Vesicles 2017, 6, 1313091. [CrossRef] [PubMed]

23. Knol, J.C.; de Reus, I.; Schelfhorst, T.; Beekhof, R.; de Wit, M.; Piersma, S.R.; Pham, T.V.; Smit, E.F.; Verheul, H.M.W.; Jiménez, C.R. Peptide-mediated "miniprep" isolation of extracellular vesicles is suitable for high-throughput proteomics. EuPA Open Proteom. 2016, 11, 11-15. [CrossRef]

24. Mitchell, J.P.; Court, J.; Mason, M.D.; Tabi, Z.; Clayton, A. Increased exosome production from tumour cell cultures using the Integra CELLine Culture System. J. Immunol. Methods 2008, 335, 98-105. [CrossRef] [PubMed]

25. Botelho, D.; Wall, M.J.; Vieira, D.B.; Fitzsimmons, S.; Liu, F.; Doucette, A. Top-down and bottom-up proteomics of SDS-containing solutions following mass-based separation. J. Proteom. Res. 2010, 9, 2863-2870. [CrossRef] [PubMed]

26. Orton, D.J.; Doucette, A.A. A universal, high recovery assay for protein quantitation through temperature programmed liquid chromatography (TPLC). J. Chromatogr. B 2013, 921-922, 75-80. [CrossRef] [PubMed]

27. Liu, H.; Sadygov, R.G.; Yates, J.R., III. A model for random sampling and estimation of relative protein abundance in shotgun proteomics. Anal. Chem. 2004, 76, 4193-4201. [CrossRef] [PubMed] 
28. Simpson, R.J.; Lim, J.W.; Moritz, R.L.; Mathivanan, S. Exosomes: Proteomic insights and diagnostic potential. Expert Rev. Proteom. 2009, 6, 267-283. [CrossRef] [PubMed]

29. Gastpar, R.; Gehrmann, M.; Bausero, M.A.; Asea, A.; Gross, C.; Schroeder, J.A.; Multhoff, G. Heat shock protein 70 surface-positive tumor exosomes stimulate migratory and cytolytic activity of natural killer cells. Cancer Res. 2005, 65, 5238-5247. [CrossRef] [PubMed]

30. Németh, A.; Orgovan, N.; Sódar, B.W.; Osteikoetxea, X.; Pálóczi, K.; Szabó-Taylor, K.É.; Vukman, K.V.; Kittel, Á.; Turiák, L.; Wiener, Z.; et al. Antibiotic-induced release of small extracellular vesicles (exosomes) with surface-associated DNA. Sci. Rep. 2017, 7, 8202. [CrossRef] [PubMed]

31. Keller, S.; Ridinger, J.; Rupp, A.-K.; Janssen, J.W.G.; Altevogt, P. Body fluid derived exosomes as a novel template for clinical diagnostics. J. Transl. Med. 2011, 9, 86. [CrossRef] [PubMed]

32. ExoCarta. Available online: http://www.exocarta.org/ (accessed on 26 July 2017).

33. Olofsson, M.H.; Ueno, T.; Pan, Y.; Xu, R.; Cai, F.; van der Kuip, H.; Muerdter, T.E.; Sonnenberg, M.; Aulitzky, W.E.; Schwarz, S.; et al. Cytokeratin-18 is a useful serum biomarker for early determination of response of breast carcinomas to chemotherapy. Clin. Cancer Res. 2007, 13, 3198-3206. [CrossRef] [PubMed]

34. Zhang, D.-H.; Tai, L.K.; Wong, L.L.; Sethi, S.K.; Koay, E.S.C. Proteomics of breast cancer: Enhanced expression of cytokeratin19 in human epidermal growth factor receptor type 2 positive breast tumors. Proteomics 2005, 5, 1797-1805. [CrossRef] [PubMed]

35. Warburg, O. On the origin of cancer cells. Science 1956, 123, 309-314. [CrossRef] [PubMed]

36. Jurisic, V.; Radenkovic, S.; Konjevic, G. The Actual Role of LDH as Tumor Marker, Biochemical and Clinical Aspects. In Advances in Cancer Biomarkers: From Biochemistry to Clinic for a Critical Revision; Scatena, R., Ed.; Springer: Dordrecht, The Netherlands, 2015; pp. 115-124, ISBN 978-94-017-7215-0.

37. Xu, R.; Pelicano, H.; Zhou, Y.; Carew, J.S.; Feng, L.; Bhalla, K.N.; Keating, M.J.; Huang, P. Inhibition of glycolysis in cancer cells: A novel strategy to overcome drug resistance associated with mitochondrial respiratory defect and hypoxia. Cancer Res. 2005, 65, 613-621. [PubMed]

38. Muñoz-Pinedo, C.; Mjiyad, N.; Ricci, J.-E. Cancer metabolism: Current perspectives and future directions. Cell Death Dis. 2012, 3, e248. [CrossRef] [PubMed]

39. Bayley, J.-P.; Devilee, P. The Warburg effect in 2012. Curr. Opin. Oncol. 2012, 24, 62-67. [CrossRef] [PubMed]

40. Young, C.D.; Anderson, S.M. Sugar and fat-That's where it's at: Metabolic changes in tumors. Breast Cancer Res. 2008, 10, 202. [CrossRef] [PubMed]

41. Hu, H.; Deng, C.; Yang, T.; Dong, Q.; Chen, Y.; Nice, E.C.; Huang, C.; Wei, Y. Proteomics revisits the cancer metabolome. Expert Rev. Proteom. 2011, 8, 505-533. [CrossRef] [PubMed]

42. Kamili, A.; Roslan, N.; Frost, S.; Cantrill, L.C.; Wang, D.; Della-Franca, A.; Bright, R.K.; Groblewski, G.E.; Straub, B.K.; Hoy, A.J.; et al. TPD52 expression increases neutral lipid storage within cultured cells. J. Cell Sci. 2015, 128, 3223-3238. [CrossRef] [PubMed]

43. Flavin, R.; Peluso, S.; Nguyen, P.; Loda, M. Fatty acid synthase as a potential therapeutic target in cancer. Future Oncol. 2010, 6, 551-562. [CrossRef] [PubMed]

44. Di Vizio, D.; Adam, R.M.; Kim, J.; Kim, R.; Sotgia, F.; Williams, T.; Demichelis, F.; Solomon, K.R.; Loda, M.; Rubin, M.A.; et al. Caveolin-1 interacts with a lipid raft-associated population of fatty acid synthase. Cell Cycle 2008, 7, 2257-2267. [CrossRef] [PubMed]

45. Wang, Y.; Kuhajda, F.P.; Li, J.N.; Pizer, E.S.; Han, W.F.; Sokoll, L.J.; Chan, D.W. Fatty acid synthase (FAS) expression in human breast cancer cell culture supernatants and in breast cancer patients. Cancer Lett. 2001, 167, 99-104. [CrossRef]

46. Notarnicola, M.; Tutino, V.; Calvani, M.; Lorusso, D.; Guerra, V.; Caruso, M.G. Serum levels of fatty acid synthase in colorectal cancer patients are associated with tumor stage. J. Gastrointest. Cancer 2012, 43, 508-511. [CrossRef] [PubMed]

47. Vazquez-Martin, A.; Colomer, R.; Brunet, J.; Lupu, R.; Menendez, J.A. Overexpression of fatty acid synthase gene activates HER1/HER2 tyrosine kinase receptors in human breast epithelial cells. Cell Prolif. 2008, 41, 59-85. [CrossRef] [PubMed]

48. Caruso Bavisotto, C.; Cappello, F.; Macario, A.J.L.; Conway de Macario, E.; Logozzi, M.; Fais, S.; Campanella, C. Exosomal HSP60: A potentially useful biomarker for diagnosis, assessing prognosis, and monitoring response to treatment. Expert Rev. Mol. Diagn. 2017, 17, 815-822. [CrossRef] [PubMed] 
49. Zou, M.; Bhatia, A.; Dong, H.; Jayaprakash, P.; Guo, J.; Sahu, D.; Hou, Y.; Tsen, F.; Tong, C.; O’Brien, K.; et al. Evolutionarily conserved dual lysine motif determines the non-chaperone function of secreted Hsp90alpha in tumour progression. Oncogene 2017, 36, 2160-2171. [CrossRef] [PubMed]

50. Graner, M.W.; Cumming, R.I.; Bigner, D.D. The heat shock response and chaperones/heat shock proteins in brain tumors: Surface expression, release, and possible immune consequences. J. Neurosci. 2007, 27, 11214-11227. [CrossRef] [PubMed]

51. Rodina, A.; Wang, T.; Yan, P.; Gomes, E.D.; Dunphy, M.P.S.; Pillarsetty, N.; Koren, J.; Gerecitano, J.F.; Taldone, T.; Zong, H.; et al. The epichaperome is an integrated chaperome network that facilitates tumour survival. Nature 2016, 538, 397-401. [CrossRef] [PubMed]

52. Grzegrzolka, J.; Kurnol, K.; Piotrow, P.; Pula, B.; Kobierzycki, C.; Piotrowska, A.; Jablonska, K.; Wojnar, A.; Rys, J.; Dziegiel, P.; et al. Hsp27 expression in invasive ductal breast carcinoma. Folia Histochem. Cytobiol. 2012, 50, 527-533. [CrossRef] [PubMed]

53. Wallenberg, M.; Misra, S.; Björnstedt, M. Selenium cytotoxicity in cancer. Basic Clin. Pharmacol. Toxicol. 2014, 114, 377-386. [CrossRef] [PubMed]

54. Wise, R.; Duhachek-Muggy, S.; Qi, Y.; Zolkiewski, M.; Zolkiewska, A. Protein disulfide isomerases in the endoplasmic reticulum promote anchorage-independent growth of breast cancer cells. Breast Cancer Res. Treat. 2016, 157, 241-252. [CrossRef] [PubMed]

55. Ramos, F.S.; Serino, L.T.R.; Carvalho, C.M.S.; Lima, R.S.; Urban, C.A.; Cavalli, I.J.; Ribeiro, E.M.S.F. PDIA3 and PDIA6 gene expression as an aggressiveness marker in primary ductal breast cancer. Genet. Mol. Res. 2015, 14, 6960-6967. [CrossRef] [PubMed]

56. Yao, J.; Jin, Q.; Wang, X.-D.; Zhu, H.-J.; Ni, Q.-C. Aldehyde dehydrogenase 1 expression is correlated with poor prognosis in breast cancer. 2017, 96, e7171. [CrossRef] [PubMed]

57. Matta, A.; Siu, K.W.M.; Ralhan, R. 14-3-3 zeta as novel molecular target for cancer therapy. Expert Opin. Ther. Targets 2012, 16, 515-523. [CrossRef] [PubMed]

58. Watson, A.P.; Evans, R.L.; Egland, K.A. Multiple functions of suchi domain containing 2 (SUSD2) in breast tumorigenisis. Mol. Cancer Res. 2013, 11, 74-85. [CrossRef] [PubMed]

59. Palumbo, R.; Gogliettino, M.; Cocca, E.; Iannitti, R.; Sandomenico, A.; Ruvo, M.; Balestrieri, M.; Rossi, M.; Palmieri, G. APEH inhibition affects osteosarcoma cell viability via downregulation of the proteasome. Int. J. Mol. Sci. 2016, 17, 1614. [CrossRef] [PubMed]

60. Wang, Q.; Zhu, L.; Jiang, Y.; Xu, J.; Wang, F.; He, Z. miR-219-5p suppresses the proliferation and invasion of colorectal cancer cells by targeting calcyphosin. Oncol. Lett. 2017, 13, 1319-1324. [CrossRef] [PubMed]

61. Zhao, X.; He, R.; Liu, Y.; Wu, Y.; Kang, L. UPregulated single-stranded DNA-binding protein 1 induces cell chemoresistance to cisplatin in lung cancer cell lines. Mol. Cell. Biochem. 2017, 431, 21-27. [CrossRef] [PubMed]

62. Piccolo, E.; Tinari, N.; Semeraro, D.; Traini, S.; Fichera, I.; Cumashi, A.; La Sorda, R.; Spinella, F.; Bagnato, A.; Lattanzio, R.; et al. LGALS3BP, lectin galactoside-binding soluble 3 binding protein, induces vascular endothelial growth factor in human breast cancer cells and promotes angiogenesis. J. Mol. Med. 2013, 91, 83-94. [CrossRef] [PubMed]

63. Zamanian, M.; Qader Hamadneh, L.A.; Veerakumarasivam, A.; Abdul Rahman, S.; Shohaimi, S.; Rosli, R. Calreticulin mediates an invasive breast cancer phenotype through the transcriptional dysregulation of p53 and MAPK pathways. Cancer Cell Int. 2016, 16, 56. [CrossRef] [PubMed]

64. Chen, A.; Rahimipour, S.; Ben-Aroya, N.; Koch, Y.; Kaganovsky, E.; Okon, E. Two forms of gonadotropin-releasing hormone $(\mathrm{GnRH})$ are expressed in human breast tissue and overexpressed in breast cancer: A putative mechanism for the antiproliferative effect of GnRH by down-regulation of acidic ribosomal phosphoproteins P1 and P2. Cancer Res. 2002, 62, 1036-1044. [PubMed]

65. Timpe, L.C.; Yen, R.; Haste, N.V.; Litsakos-Cheung, C.; Yen, T.Y.; Macher, B.A. Systemic alteration of cell-surface and secreted glycoprotein expression in malignant breast cancer cell lines. Glycobiology 2013, 23, 1240-1249. [CrossRef] [PubMed]

66. Bateman, N.W.; Sun, M.; Hood, B.L.; Flint, M.S.; Conrads, T.P. Defining central themes in breast cancer biology by differential proteomics: Conserved regulation of cell spreading and focal adhesion kinase. J. Proteome Res. 2010, 9, 5311-5324. [CrossRef] [PubMed] 
67. Shin, J.; Kim, G.; Lee, J.W.; Lee, J.E.; Kim, Y.S.; Yu, J.H.; Lee, S.T.; Ahn, S.H.; Kim, H.; Lee, C. Identification of ganglioside GM2 activator playing a role in cancer cell migration through proteomic analysis of breast cancer secretomes. Cancer Sci. 2016, 107, 828-835. [CrossRef] [PubMed]

68. Zhang, D.; Tai, L.K.; Wong, L.L.; Chiu, L.-L.; Sethi, S.K.; Koay, E.S.C. Proteomic study reveals that proteins involved in metabolic and detoxification pathways are highly expressed in HER-2/neu-positive breast cancer. Mol. Cell. Proteom. 2005, 4, 1686-1696. [CrossRef] [PubMed] 